\title{
LA JURISPRUDENCIA MEXICANA Y EL PRINCIPIO DE LEGALIDAD: UNA COMPLEJA RELACIÓN*
}

\author{
BINDING CASE LAW AND PRINCIPLE OF LEGALITY \\ IN MEXICO: A COMPLEX RELATIONSHIP
}

\section{Sandra GÓMORA JUÁREZ**}

RESUMEN: El presente artículo sostiene que la trascendental reforma constitucional de 2011 en materia de derechos humanos, a la que se hace referencia como "el cambio de paradigma" en México, es incapaz, por sí misma, de sortear todos los obstáculos de un orden jurídico cuyas prácticas permanecen ancladas al siglo XIX. Por ello, este trabajo analiza nuestra concepción de legalidad en materia administrativa, y sugiere transitar a una legalidad más robusta, al tiempo que invita a repensar la configuración de nuestra jurisprudencia, mecanismos todos ellos para coadyuvar a una efectiva protección de derechos humanos en México.

Palabras clave: legalidad, jurisprudencia, derechos humanos, autoridad administrativa.
ABSTRACT: This article argues that the momentous constitutional reform of 2011 in the field of human rights, which is referred to as "the paradigm shift" in Mexico, is unable by itself to overcome all the obstacles of a legal order whose practices remain anchored to the 19th century. Therefore, this paper analyzes our conception of legality in administrative matters and suggests moving to a more robust legality while inviting us to rethink the configuration of binding case law. These mechanisms will contribute to an effective protection of human rights in Mexico.

Keyzeords: Principle of Legality, Case Law, Human Rights, Administrative Authority.

* Artículo recibido el 23 de enero de 2019 y aceptado para su publicación el 3 de agosto de 2019.

** ORCID: 0000-0002-9164-6194. Investigadora de tiempo completo en el Instituto de Investigaciones Jurídicas de la UNAM, en el campo de filosofía y teoría del derecho; miembro del Sistema Nacional de Investigadores (SNI) y directora de Problema. Anuario de Filosofia y Teoría del Derecho, del propio Instituto. Correo electrónico: sgomoraj@unam.mx.

Boletín Mexicano de Derecho Comparado, nueva serie, año LI, núm. 155, mayo-agosto de 2019, pp. 799-839. 
SUMARIO: I. Introducción. II. El principio de legalidad y el sistema jurídico mexicano. III. La jurisprudencia mexicana y la naturaleza del precedente judicial. IV. Del principio de legalidad administrativa. V. Hacia una legalidad robusta. VI. Conclusiones. VII. Bibliografia.

\section{INTRODUCGIÓN}

En México, en el discurso jurídico solemos identificar las reformas constitucionales del 6 y 10 de junio de 2011 como constitutivas de un "cambio de paradigma" en la manera en que se concebían y protegían los derechos humanos. Efectivamente, la llegada de tales reformas constitucionales fue disruptiva y extraordinaria porque, a partir de su irrupción en el orden constitucional mexicano, los derechos humanos comenzaron a ser considerados como parámetros de validez constitucional de toda actuación de autoridad.

No obstante, esta reforma vanguardista y progresista carece de la capacidad de sortear por sí misma todos los obstáculos que plantea un orden jurídico, cuyas prácticas e instituciones jurídicas permanecen ancladas al siglo XIX. A pesar de la modificación constitucional y la progresiva incorporación judicial al orden jurídico de los mandatos constitucionales sobre derechos humanos, no se advierten grandes avances en los órganos de la administración pública en la materia.

Sostendré que la transición plena del Estado de derecho al Estado constitucional de derecho no podrá concretarse hasta en tanto los operadores y las instituciones con que se ha de materializar el cambio de paradigma en México - como es el caso de la jurisprudencia y el principio de legalidadse conciban en términos de lo que este modelo requiere, lo cual hasta ahora no ha ocurrido, ya que, a siete años de distancia de la reforma constitucional en materia de derechos humanos, su aplicación, operación e impacto siguen siendo muy limitados.

Sugeriré que, tanto la concepción que mantenemos acerca de la legalidad de las autoridades administrativas, como la configuración actual de nuestra jurisprudencia (creada y pensada como institución del siglo XIX) son insuficientes para afrontar y atender los retos que el país enfrenta hoy en materia de derechos humanos. Esta situación nos plantea la necesidad de repensar nuestra propia concepción de legalidad - para considerar una 
concepción más robusta-, así como los elementos formales que caracterizan a la jurisprudencia mexicana - comenzando por su alcance - a la luz de las obligaciones internacionales del Estado mexicano en la materia.

\section{EL PRINCIPIO DE LEGALIDAD Y EL SISTEMA JURÍDICO MEXICANO}

Es innegable que el Estado de derecho ha sido una noción central en la historia moderna del Estado y del derecho mismos, desde su origen - a finales del siglo XVIII - hasta nuestros días ha sido el eje fundamental de configuración de los Estados modernos, que marcó un cambio de paradigma de seguridad y protección de los ciudadanos frente a la arbitrariedad imperante (García Ricci, 2011: 21-22).

En tal sentido, el principio de legalidad está ligado ineludiblemente al Estado moderno y ha desempeñado la importante función, no sólo de garantizar los derechos fundamentales de los ciudadanos, sino también de limitar la actividad punitiva del Estado (Bergalli, 1998: 59).

En los inicios del Estado de derecho se revalorizó la ley y su papel como el elemento para eliminar las arbitrariedades, de modo que jugó un papel central aun cuando se trataba de una legalidad puramente formal, según la cual nadie está por encima de la ley (García Ricci, 201 1: 37; Vignolo, 2011 : 788).

Con su surgimiento, a las Constituciones se les concibió como el instrumento para sujetar el Estado al derecho, pero además adoptaron (en su parte dogmática) la Declaración de los Derechos del Hombre y del Ciudadano de 1789, por lo que entre sus tareas se agregó la de garantizar los derechos humanos (García Ricci, 2011 : 31 y 36).

Esta configuración permitió brindar certeza al ciudadano al saber que los órganos estatales sólo pueden actuar con fundamento en algún precepto legal. Hans Kelsen explicó claramente la sustancia de esta noción al referirse a la distinción entre un individuo que es parte de la administración pública y uno que no lo es: "Un individuo que no funciona como órgano del Estado puede hacer todo aquello que no está prohibido por el orden jurídico, en tanto que el Estado, esto es, el individuo que obra como órgano estatal, solamente puede hacer lo que el orden jurídico le autoriza a realizar" (Kelsen, 1979: 313). 
Sin embargo, el Estado liberal de derecho, con su desarrollo de legalidad, no fue suficiente para limitar la arbitrariedad - como atestiguó el siglo XX - ya que las leyes se pueden modificar para permitir legalmente la actuación arbitraria. Se hizo preciso considerar entonces, la posibilidad de que el Estado de derecho incluyera un contenido material complementario, que ordenara la actividad estatal (Vignolo, 2011: 790), de modo que, para evitar las funestas consecuencias de la manipulación del derecho, se encontró una nueva fórmula jurídica en la que todas las leyes debían adaptarse a la Constitución, pasando así, del Estado liberal de derecho al Estado constitucional de derecho (García Ricci, 2011: 40).

El tránsito al Estado constitucional de derecho recogió, como nuevo requisito de validez de las leyes, su adecuación al contenido de la Constitución, que es la ley suprema del propio Estado. Se incorporaron nuevos elementos al Estado constitucional de derecho que le dan su configuración actual: la supremacía de los derechos fundamentales sobre las leyes y actos estatales de autoridad, así como la incorporación de un sistema de justicia constitucional para garantizarlos (Ferrer, 2018: 664; García Ricci, 2011 : 40-42).

Con la elaboración de documentos internacionales que recogieran los derechos a manera de estándar internacional con órganos de supervisión y control, dio inicio el proceso de internacionalización del derecho constitucional de los derechos humanos (Ferrer, 2018: 665). La incorporación en el ámbito interno de los Estados de ese derecho internacional de los derechos humanos, se ha llevado a cabo de diversas maneras con fórmulas que han permitido ahora el proceso inverso de constitucionalización del derecho internacional de los derechos humanos (Ferrer, 2018: 664-671).

Tal ha sido la travesía y configuración de la mayoría de los Estados modernos, y el caso mexicano no es la excepción. Actualmente, la Constitución mexicana recoge de manera formal todas las anteriores características para otorgarle la etiqueta de Estado constitucional de derecho, que a su vez reflejan el principio de legalidad al que se sujeta el Estado.

El contenido de la Constitución mexicana refleja que hay supremacía constitucional (artículo 133); existe división de poderes (artículo 49), el Congreso de la Unión emite las leyes conforme a un procedimiento previamente establecido (artículos 71-73); los actos de autoridad se deben sujetar a la Constitución y el juicio de amparo protege los derechos de los ciudadanos de posibles violaciones (artículos 103 y 107); hay control judi- 
cial de la constitucionalidad de los actos de autoridad (artículo 105); está prohibida la retroactividad de la ley; existe el derecho al debido proceso; persiste la exacta aplicación de la ley en materia penal y aplicación conforme a la ley o su interpretación en materia civil (artículo 14) y, finalmente, se contemplan los requisitos de los actos de autoridad (artículo 16) (Salazar, 1998: 201).

Además de contener los derechos antes señalados en la parte dogmática, gracias a la reforma constitucional en materia de derechos humanos de 2011, la Constitución Política de los Estados Unidos Mexicanos reconoce y garantiza los derechos humanos reconocidos en los tratados internacionales de los que México es parte. Adicionalmente, establece que las normas jurídicas relativas a derechos humanos se interpretarán de conformidad con la Constitución y con los tratados internacionales y que todas las autoridades locales en el ámbito de su competencia tienen la obligación de promover, respetar, proteger y garantizar los derechos humanos de conformidad con los principios de universalidad, interdependencia, indivisibilidad y progresividad.

Por ello es que sigue vigente la reflexión que hiciera hace dos décadas Pedro Salazar, cuando sostenía que el aspecto dinámico del sistema legal mexicano no logra ser garantía de seguridad y certeza jurídicas (Salazar, 1998: 200). Si bien, el objetivo de la observación en el momento actual se dirige a llamar la atención en torno a la necesidad de una concepción más amplia del principio de legalidad (inherente al Estado de derecho), que ya desde entonces Salazar vislumbraba, es ineludible que hoy en día la efectiva aplicación de normas jurídicas a casos concretos se mire en un contexto ampliado, distinto y más complejo de aquel en el que se concibió.

\section{LA JURISPRUDENCIA MEXICANA Y LA NATURALEZA DEL PREGEDENTE JUDICIAL}

\section{La jurisprudencia mexicana}

En México, hablar de jurisprudencia nos remite a los criterios interpretativos contenidos en las sentencias judiciales de los tribunales autorizados para ello por la Ley de Amparo, pensemos en las salas de la Suprema Corte de Justicia de la Nación (SCJN), los plenos de circuito y los tribunales colegia- 
dos de circuito. Cuando se habla de precedentes, se hace referencia a los criterios interpretativos aislados, contenidos en las sentencias judiciales de los tribunales autorizados para ello, que aún no cumplen el número de reiteraciones necesarias para formar jurisprudencia.

Aunque algunas Constituciones de las entidades federativas facultan al pleno de los tribunales superiores de justicia para crear su propia jurisprudencia sobre legislación local, lo cierto es que los sistemas de creación de jurisprudencia estatales son débiles y sus criterios son poco citados, pues recordemos que los tribunales locales están obligados por la jurisprudencia federal. En lo que sigue, me referiré a la jurisprudencia para hablar solamente de aquella que establecen los tribunales federales autorizados.

La jurisprudencia, pues, contiene criterios interpretativos que los tribunales establecen en la aplicación e interpretación del contenido jurídico normativo vigente, que incluye también normas jurídicas convencionales de los que México es parte. Dichos criterios se originan gracias a que los particulares someten sus demandas al examen de los órganos judiciales para que resuelvan, que en los casos parcialmente determinados, requieren un ejercicio interpretativo que permita concretar, delinear y dotar de contenido a ciertos derechos y normas jurídicas en contextos específicos.

Esta labor permite materializar y hacer efectivo el ejercicio de los derechos cuya enunciación permanece en términos abstractos en las diferentes normas jurídicas, además de que su divulgación sistematizada “...responde a la necesidad social de conocerla, y, en esa medida, allegar la información mínima que permita la tarea de fiscalización ciudadana sobre el tribunal constitucional" (Herrera, 2015: 17).

Existen diversos sistemas de creación jurisprudencial en México, es decir, formas a través de las cuales se generan los criterios autoritativos; sin embargo, un rasgo característico de la jurisprudencia que ha permanecido con ella desde su origen es que estos criterios interpretativos son de aplicación obligatoria para las autoridades judiciales federales y locales únicamente.

Este rasgo en sí mismo no debería sorprendernos, dado que se trata de una institución que surgió en el contexto del siglo XIX en el que el principio de "división de poderes" era el centro de atención primario. Lo que sí debería sorprendernos es la falta de reflexión crítica con relación a su configuración, particularmente con su alcance, cuando en pleno siglo XXI, en un contexto distinto que demanda al Estado mexicano resultados par- 
ticulares, éste no ha sido capaz de dar cumplimiento a sus obligaciones en materia de derechos humanos.

\section{Origen y configuración de la jurisprudencia mexicana}

Es sabido que el origen de la jurisprudencia mexicana está ligado al juicio de amparo. El contexto histórico promovió que ambas instituciones se dieran sustento mutuo, pues

...paulatinamente las sentencias constitucionales contribuyeron a moldear y desarrollar el juicio de amparo, aclarando muchísimos de sus aspectos procesales, de tal suerte que, así como la jurisprudencia surge de éste, también incide en él, por lo cual se puede afirmar que estamos en presencia de una evolución donde se dan influencias recíprocas. ${ }^{1}$

Este pasaje permite dimensionar la centralidad e importancia que ambas instituciones tuvieron en el contexto histórico mexicano y cuyo impacto ha trascendido hasta nuestros días.

La Constitución de los Estados Unidos Mexicanos promulgada el 4 de octubre de 1824, fue el primer documento con vigencia eficaz en el México independiente, que a su vez revistió una singular importancia, pues fue la primera que estableció de manera efectiva un sistema judicial estructurado constitucionalmente (Fix-Zamudio y Cossío, 2003: 113-114).

Con la Constitución liberal de 1857, se estableció definitivamente en los artículos 101 y 102, el derecho de amparo como un medio de control constitucional contra leyes o actos de las autoridades que violaran las garantías individuales, o bien, restringieran la soberanía de los estados. Es de mencionar que, la aplicación del amparo fue efectiva hasta 1861, debido a los problemas bélicos que enfrentaba el país y a la falta de procedimientos idóneos para su aplicación, principalmente (Acosta, 1998: 22).

1 Lucio Cabrera (2002: 231-233) advierte que el surgimiento de la jurisprudencia en México y sus influencias recíprocas con el juicio de amparo se debieron principalmente a tres circunstancias: 1) que las sentencias federales de amparo gozaban de mayor prestigio que las emitidas por tribunales comunes; 2) que se requería revestir de mayor certidumbre y seguridad jurídicas a las decisiones de los tribunales federales, lo cual se lograría obligándolos a sostener sus criterios, y 3) que se requería remediar los constantes cambios de opinión que generaba la constante movilidad de ministros durante el porfiriato. Así es como la jurisprudencia nació ligada al amparo y a las sentencias constitucionales. 
En la práctica judicial y ante la falta de reglas procesales adecuadas, los jueces fueron definiendo los aspectos procesales que, aún hoy, definen al juicio de amparo, pues los propios juzgadores fueron sentando las bases de lo que más adelante configuraría las características esenciales del juicio de amparo (Acosta, 1998: 22-23).

La Constitución de 1857 ya estipulaba que las sentencias se debían publicar en un periódico, mismo que fue creado por el entonces presidente de la República, Benito Juárez García, mediante decreto el 8 de diciembre de 1870. Dicho periódico, creado para la publicación de las sentencias definitivas (de 1867 en adelante) de los tribunales federales, llevó el nombre de Semanario Fudicial de la Federación (Guerrero, 1984: 12).

Durante la vigencia de la Constitución de 1857, se expidió en noviembre de 1861, la ley orgánica de los artículos 101 y 102 constitucionales, es decir, la primera Ley de Amparo. Ante la necesidad de subsanar las deficiencias de esta Ley - de las que, el maestro Burgoa opina, eran inevitables por tratarse del primer ensayo de organización y reglamentación de una nueva institución (Burgoa, 2004: 137)-, como las imperfectas normas procedimentales, los múltiples criterios de interpretación y los alcances del nuevo juicio. Años después, el 30 de octubre de 1868, Ignacio Mariscal, entonces ministro de Justicia, presentaría una iniciativa de Ley de Amparo.

La iniciativa presentada por Ignacio Mariscal fue aprobada - después de intensos debates - el 19 de enero de 1869, y promulgada el día siguiente con el título de Ley Orgánica Constitucional sobre el Recurso de Amparo (SCJN, 2005: 58). Dos importantes aportaciones se derivaron de esta Ley con relación a la jurisprudencia: la publicación de las sentencias de amparo y la determinación de la cualidad de que los criterios vertidos en las sentencias se convirtieran en obligatorios para otros órganos jurisdiccionales.

La gran diversidad de criterios surgidos de la interpretación de la Constitución por parte de las jueces de distrito provocó la necesidad de implantar la fórmula (traída del common law), según la cual, las decisiones de los órganos superiores se constituyen como obligatorias para los órganos inferiores. Esta medida contribuyó a evitar que la Constitución fuera interpretada en sentidos opuestos y propició la unificación de criterios al erigirse la Suprema Corte como la responsable de la interpretación constitucional (Cabrera, 2002: 238, 239, 241 y 242).

Tiempo después, nuevamente se buscó reformar la Ley Orgánica Constitucional sobre el Recurso de Amparo de 1869. De las propuestas plantea- 
das, se aprobó la iniciativa presentada en 1881, por el ministro de Justicia, Ezequiel Montes, la cual estuvo inspirada por el pensamiento de Ignacio L. Vallarta, e influenciada de manera indirecta por el pensamiento de Ignacio Mariscal.

Mariscal consideraba que las sentencias de amparo alcanzaban un doble propósito: el primero, resolver el caso concreto, y el segundo, interpretar el derecho público y constitucional. Por su parte, Ignacio Vallarta, consideraba que tales fines sólo se podrían alcanzar mediante el pronunciamiento de cinco sentencias consecutivas en el mismo sentido (SCJN, 2005: 63).

Así fue como en la Ley de Amparo de $1882^{2}$ apareció formalmente la jurisprudencia en el derecho positivo, pues en ella se estableció la obligatoriedad de la interpretación fijada por la Corte en cinco ejecutorias, y se estipuló que las sentencias de la Suprema Corte debían estar fundadas. Si bien es cierto que desde 1870 surgió el Semanario Fudicial de la Federación, también lo es que las sentencias publicadas antes del Semanario, no tenían las características propias que la institución tiene actualmente.

Más adelante, la promulgación de la Constitución de 1917 marcó el rumbo de la jurisprudencia, pues al cambiar la norma fundamental, aquella emitida bajo las normas constitucionales de 1857 quedó inoperante. A partir de ese momento, debía comenzar a crearse la jurisprudencia aplicable, bajo las normas constitucionales vigentes.

Con la Constitución de 1917 se expidió una nueva Ley de Amparo (en 1919), que ampliaba el ámbito competencial para emitir jurisprudencia, cuya esfera de obligatoriedad se extendía ahora también a los tribunales de los estados (SCJN, 2005: 47).

La jurisprudencia fue elevada a rango constitucional con las reformas a la ley fundamental del 19 de febrero de 1951, en las que, por primera vez, la Constitución Política la menciona (Acosta, 1998: 48). Además, las reformas incluyeron aspectos relacionados con la resolución de tesis contradictorias y con las modificaciones de los artículos relativos a su formación, modificación y obligatoriedad.

Hubo nuevas reformas constitucionales en 1967, relativas a la concurrencia de la Corte y los tribunales colegiados para conocer asuntos y

2 Aprobada el 8 y 11 de noviembre de 1882 por las cámaras de Diputados y de Senadores, respectivamente (Cabrera, 2002: 246-247). 
cuestiones de legalidad; la separación de la competencia por materia, cuantía, grado, trascendencia, entre otros. Aunque resulta importante subrayar que la emisión de jurisprudencia obligatoria seguía siendo facultad sólo de la Suprema Corte y que la interpretación jurisprudencial abarcó tanto leyes como reglamentos locales. ${ }^{3}$

Con el establecimiento de las facultades jurisprudenciales de los tribunales colegiados, terminó la Sexta Época y comenzó la Séptima Época del Semanario Fudicial de la Federación. En 1987, nuevamente hubo modificaciones a la Ley de Amparo, entrando en vigor en 1988, por las que se concedió el total control de la legalidad a los tribunales colegiados de circuito. Aun así, la Suprema Corte decidió mantener el criterio con relación a la resolución de contradicciones de tesis.

En 1994, la Constitución fue modificada nuevamente sobre aspectos fundamentales como: la estructura de la Corte, régimen de los ministros, nueva competencia constitucional de la Corte y el Consejo de la Judicatura, entre otras (Hernández, 2008: 279; Valencia, 1995: 414). El Pleno de la Corte, se volvió a integrar con once ministros, a fin de facilitar la deliberación y propiciar la interpretación coherente; la duración de su encargo se estableció de quince años máximo (sin perder la inamovilidad); se estableció la competencia exclusiva de la SCJN para conocer de controversias constitucionales y acciones de inconstitucionalidad; y para aliviar la carga de trabajo administrativo del Poder Judicial se creó el Consejo de la Judicatura Federal (Cabrera, 2002: 255-261).

Posteriormente, la Ley de Amparo fue reformada en 1999, habilitando a la Corte para emitir acuerdos generales con el propósito de decidir qué asuntos conocería y cuáles remitiría a los tribunales colegiados. Nuevamente, en junio de 2000, se reformó la citada ley en lo relativo a la actual integración de la Suprema Corte, los requisitos para establecer jurisprudencia, determinar su interrupción y la terminación de su obligatoriedad (SCJN, 2005: 88).

La más reciente reforma a la Constitución, en junio de 2011, introdujo modificaciones relacionadas con la jurisprudencia, a saber, se crean los plenos de circuito para establecer criterios interpretativos, junto con los requi-

3 A partir de la reforma aludida, se facultó expresamente a la Suprema Corte para establecer jurisprudencia sobre leyes y reglamentos federales o locales, además de la Constitución Política (Castro, 1971: 40). 
sitos de su interrupción y sustitución. No obstante, la "fórmula Otero" tan característica del amparo mexicano, el número de reiteraciones y el alcance de la jurisprudencia nunca han sido revaluados, sino que tales rasgos han sido constantes desde el siglo XIX hasta nuestros días. ${ }^{4}$

\section{La naturaleza e importancia del precedente judicial}

El precedente judicial, referido a las sentencias — más propiamente, a los razonamientos contenidos en ella - de tribunales judiciales en un sistema jurídico con fuerza autoritativa que muestra a otros tribunales la forma de resolver controversias en casos semejantes, es una institución central en los sistemas jurídicos contemporáneos.

La práctica de confiar en la labor previa de tribunales autorizados, esto es, en los razonamientos previos que generan soluciones a cuestiones jurídicas que no encontraban una respuesta en el ordenamiento jurídico vigente por la razón que fuera, ha sido constante en diversos países, si bien con diversos matices.

Gradualmente hemos transitado (en los sistemas jurídicos de derecho escrito) hacia una conciencia de que la labor interpretativa judicial permite mantener actualizado al sistema jurídico en las diferentes ramas del derecho, que permite, además, delinear y asignar contenidos que las leyes no especifican o dejan abiertos para su aplicación, y que permite también dotar de significado y alcance a los derechos humanos en el contexto de los sistemas jurídicos particulares, lo cual no es labor fácil.

En ese proceso de descubrimiento, de manera especialmente destacada, ha sido la judicatura la responsable de impulsar los cambios y modificaciones más urgentes y trascendentales en la manera de aproximarse y entender las verdaderas dimensiones de los derechos humanos en el Estado mexicano. Mediante diversas sentencias relevantes la judicatura ha ido marcando la pauta de desarrollos jurisprudenciales cada vez más sólidos y protectores. $^{5}$

4 Con excepción del actual artículo 107 constitucional que delinea la declaración general de inconstitucionalidad de una norma general.

5 Véase, por ejemplo, el importante desarrollo elaborado en el amparo directo civil 6/2008 y la jurisprudencia derivada en el que la SCJN (de México) tuvo ocasión de analizar la solicitud y características de la rectificación de acta de nacimiento de una persona por cambio de sexo. Hasta ese momento, la legislación aplicable no contemplaba la po- 
Desde la sede judicial se ha interpretado gradualmente el derecho mexicano con lecturas cada vez más amplias e incluyentes que permiten ir atendiendo los diversos aspectos de las interacciones sociales que las leyes no contemplan plenamente y que, difícilmente, obtendrán atención efectiva en sede legislativa. Por ello, es de la mayor importancia el desarrollo jurisprudencial, así como el análisis en torno al mismo, pues los órganos jurisdiccionales tienen en sus manos la atribución permanente de asignar significados para casos presentes y futuros en el derecho.

En esa misma línea se reconoce la importancia del papel de los criterios interpretativos autoritativos en el marco de la argumentación en sede judicial ante el conflicto entre derechos. De tal envergadura es la jurisprudencia que se afirma, que incluso el ejercicio de la proporcionalidad en la práctica constitucional no sería plausible sin precedentes (reglas-resultado de la ponderación) (Clérico, 2015: 77).

$\mathrm{Al}$ argumentar a favor de un modelo de ponderación orientado por reglas, Laura Clérico establece que la jurisprudencia contiene parte de las reglas que orientan a la ponderación, ${ }^{6}$ que se manifiestan como una red de "mandatos de consideración" que ayudan a determinar la intensidad y peso de la restricción de derechos. En concreto, la jurisprudencia proporciona la historia del peso de un principio bajo determinadas condiciones y frente a principios colisionantes, proporcionando así, soluciones para futuros casos o mostrando el sentido que debe tomar la justificación de la solución (Clérico, 2015: 94). ${ }^{7}$

sibilidad de rectificación de acta en esas circunstancias. El tribunal autoritativo hizo una interpretación en la que no sólo analizó las normas jurídicas parcialmente aplicables, sino que incluso avanzó explicaciones y respuestas antes no contempladas por el derecho, como producto del análisis del caso. Además, este análisis se realizó con anterioridad a la reforma de 2011 en materia de derechos humanos (SCJN, 2007, Amparo directo civil 6/2008, relacionado con la Facultad de atracción 3/2008-PS).

6 Las reglas extraídas de la conjunción de los siguientes elementos proporcionan previsibilidad procedimental a la práctica argumentativa de la ponderación: a) el discurso jurisprudencial concreto sobre resolución de conflictos de derechos; b) la dogmática constitucional sobre teoría de los derechos, y c) las herramientas argumentativas que surgen de los avances que se dan en la teoría del derecho (Clérico, 2015: 89-90).

7 Existe una semejanza en la posiciones de Clérico y las mías, en cuanto a la idea de que las interpretaciones posibles, que el tribunal puede intentar, están limitadas por el material jurídico existente, y no son, por tanto, infinitas o arbitrarias. Para un desarrollo más detallado de este argumento, véase Gómora-Juárez (2018). 
Así pues, otra de las valiosas aportaciones de la jurisprudencia se lee desde la solución de casos constitucionales que implican colisiones de derechos; aquí, el marco que provee la determinación del peso abstracto y la intensidad de restricción de los derechos en conflicto está dado precisamente por esta institución.

Es central no perder de vista que la relevancia - llamémosla "interna"- de la jurisprudencia en el proceso de argumentación trasciende la propia esfera judicial ya que, si bien es muy importante en el proceso de solución de controversias en sede judicial, los criterios o soluciones que contiene moldean nuestra práctica jurídica.

En tal sentido, es interesante advertir que la nueva Ley de Amparo reconoce tres sistemas de creación de jurisprudencia: ${ }^{8}$ por reiteración de criterios, por contradicción de tesis y por sustitución (Ley de Amparo, 2013: artículos 215-230). A través de estos sistemas es posible crearla, por lo que, una vez satisfechos los requisitos formales de creación se cuenta con criterios de aplicación obligatoria que, en el contexto mexicano y dada su publicidad, es posible conocer y aplicar a los casos semejantes. No obstante, esta obligación de "conocer y aplicar" jurisprudencia está restringida a los órganos judiciales, aun cuando ésta se considera una fuente del derecho mexicano.

$\mathrm{Al}$ respecto, es evidente que en nuestro sistema jurídico se ha ignorado o demeritado durante mucho tiempo el papel que tiene la jurisprudencia debido a que tenemos un sistema de derecho codificado. Tal afirmación se ha esgrimido como si se tratara de un argumento absoluto e irrefutable de configuración de la institución, a la luz del cual hemos observado el papel de la jurisprudencia y el precedente con la lente del más estricto legalismo, según fue concebido en sus orígenes.

Sin embargo, ya no es posible negar la centralidad que los criterios interpretativos, emanados de los tribunales autorizados, tienen en la actualidad del derecho mexicano en pleno siglo XXI, particularmente en materia constitucional y sobre derechos humanos, de manera transversal. Esta realidad nos urge a repensar el papel de la jurisprudencia mexicana en el contexto jurídico actual.

8 En este trabajo me refiero a la jurisprudencia creada mediante alguno de estos sistemas como resultado de las sentencias de amparo.

Esta obra está bajo una Licencia Creative Commons Atribución-NoComercial-SinDerivar 4.0 Internacional, IIJ-UNAM. Boletín Mexicano de Derecho Comparado, núm. 155, mayo-agosto de 2019, pp. 799-839. 


\section{DEL PRINCIPIO DE LEGALIDAD ADMINISTRATIVA}

El planteamiento originario del principio de legalidad administrativa postulaba la creación de "la administración" como una entidad abstracta cuyos actos no procedían de un soberano, sino de esta entidad sometida a la ley. En este sentido, la administración no podía actuar con propia autoridad, sino al amparo de la autoridad de la ley como expresión legítima de la voluntad de la comunidad (García de Enterría, 1974: 442-443). De ahí que, históricamente, la creación de la administración y el principio de legalidad significaran un cambio radical en la concepción del sistema jurídico.

Siguiendo la concepción originaria del principio de legalidad de la administración pública, ésta se encuentra sujeta a la ley que establece y acota su actuación. Así, el principio de legalidad implica la sujeción plena de la administración pública a la ley que, al proveerle de un marco jurídico, la habilita para actuar y define los límites de dicha actuación a través de la concesión de potestades (García de Enterría, 1974: 449; Rubio, 1993: 21-22). Los particulares, en contraposición, están sujetos a los efectos jurídicos que producen dichas potestades, que pueden ser ventajosos o desventajosos (García de Enterría, 1974: 451).

$\mathrm{Al}$ respecto, si bien es cierto que la legalidad administrativa implica la sujeción de los órganos de la administración pública a la ley, también lo es que la legalidad implica el sometimiento de la propia ley a la Constitución, lo cual determina su propia validez. García de Enterría lo llamó "sometimiento al sistema de valores materiales que la Constitución proclama", lo cual implica que aquellos postulados explícitos de la Constitución, como principios básicos y derechos humanos, han de impregnar la aplicación de la legislación que abreva de y es portadora de ese sistema de valores (García de Enterría, 1984: 14-15).

De modo que “...la ley no se limita a hacer posible una actuación del gobierno que sin ella no lo sería, sino que incide directamente sobre los derechos y deberes de los ciudadanos, [y con ello] ha de tener necesariamente una estructura material determinada..." (Rubio, 1993: 33). De lo que se trata es de "volver a una categoría básica del Estado de derecho, cuya sustancia es precisamente la garantía de la libertad” (Rubio, 1993: 33).

9 Una de las funciones del poder público es la función ejecutiva, que se lleva a cabo a través de la administración pública, entendida como la "organización que tiene a su cargo la dirección y gestión de los negocios estatales ordinarios", es también la actividad que desarrollan los órganos del Estado para el cumplimiento de sus fines (Márquez, 2005: 53-54). 
En tal sentido, tanto García de Enterría (1984: 20) como Rubio Llorente (1993: 29-30) coinciden al advertir que, en el marco de un sistema constitucional, la ley no puede pensarse sólo en su sentido formal - como una simple autorización a la administración púbica concedida por el legislador-, sino también ha de pensarse en su aspecto material, so pena de no cubrir las exigencias constitucionales de un sistema material de valores.

Ahora bien, la labor de la rama administrativa del Estado es central para la ejecución de las normas jurídicas y la conducción del propio Estado, de ahí la importancia de insistir en el análisis de sus actos. Hemos de tener en cuenta que la autoridad administrativa emite actos administrativos que son en sí mismos jurídicos y unilaterales en el ejercicio de su potestad, cuya consecuencia es crear, reconocer, modificar, transmitir o extinguir una situación jurídica subjetiva, pero cuya finalidad última es la satisfacción del interés general (Serra, 1998: 238).

Lo cierto es que, aunque el acto administrativo es unilateral y su emisión goza de una presunción de validez por razones prácticas, ésta no es absoluta y no es razonable admitir - en el contexto constitucional en que nos encontramos - que los actos administrativos descansen en la aplicación ciega de la ley sin tomar en consideración la riqueza de la jurisprudencia que versa sobre esa misma ley (Palomo, 2015: 47-59).

La limitación del actuar de los órganos administrativos tiene una justificación que radica en la protección de la esfera de los particulares de potenciales abusos y arbitrariedades, pero ¿qué ocurre si esa justificación deja de brindar sustento cuando la decisión del órgano administrativo amplía, promueve o fortalece el ejercicio de derechos del particular, mediante la aplicación de jurisprudencia? ¿Sería razonable considerar dicha actuación como una violación al principio de legalidad administrativa? Estos cuestionamientos serán estudiados con mayor detenimiento en las secciones siguientes.

\section{La relación principio de legalidad-jurisprudencia}

La revisión histórica acerca de la configuración de la jurisprudencia mexicana da testimonio de la forma en la que la legislación la ha regulado, y la doctrina la ha caracterizado y clasificado, con la tendencia permanente a concebir su vocación orientadora limitada al ámbito jurisdiccional, lo que nos lleva a hablar acerca de su relación con el principio de legalidad. 
Podríamos decir que nuestra jurisprudencia no ha experimentado diversas "facetas" formales, sino que se ha mantenido prácticamente inalterada, casi indiferente al proceso de internacionalización del derecho constitucional y posterior constitucionalización del derecho internacional de los derechos humanos. Esta circunstancia tiene por supuesto implicaciones importantes.

En México, como en otros países latinoamericanos de origen, se ha concedido, tanto en la legislación como en la doctrina, un papel muy limitado a la jurisprudencia como una fuente secundaria, incluso marginal, de derecho. ${ }^{10}$ Tradicionalmente, se entendía la función de los tribunales como la mera aplicación mecánica de la ley, ya que todas las respuestas estaban ya contenidas en ella, con lo cual no se admitía que la actividad jurisdiccional desempeñara un papel distinto a la aplicación.

Sin embargo, tal concepción se fue erosionando y se vio rebasada por una realidad que discurre con una velocidad vertiginosa. El tiempo mostró que el discurso, según el cual las respuestas a todos los problemas están en la ley, era falso, lo que condujo a la necesidad de reconocer abierta, aunque gradualmente, el papel creador de la jurisprudencia, con lo cual en la práctica, "el principio de legalidad tuvo que ensancharse para admitir la llegada del poder complementador e innovador de la jurisprudencia" (López, 2015: 15). ${ }^{11}$

Hablar de la ampliación del principio de legalidad que concedió un papel más central a la jurisprudencia parecería inexacto ya que desde sus orígenes, la Constitución y la ley de amparo mexicana han reconocido la obligatoriedad de la jurisprudencia en el ámbito jurisdiccional, no obstante, en el discurso y la práctica se había negado sistemáticamente esa realidad relegando su papel al mínimo.

Esta ampliación a la noción de legalidad tuvo que operar en el nivel del discurso y la práctica, principalmente, ya que ni constitucional ni legalmente había obstáculo alguno para reconocer la importancia creadora de

10 La experiencia colombiana es también un ejemplo de esto (López, 2015: 14).

11 Si bien Medina describe así la situación colombiana, la explicación es perfectamente adecuada para el caso mexicano. En el marco de esta discusión resulta por demás interesante advertir el camino de transformación que ha seguido la jurisprudencia colombiana, el que la Corte Constitucional le ha dado tal fuerza que se considera que la jurisprudencia se ha fundido con el sentido de la norma de origen legal, de modo que el desconocimiento jurisprudencial puede ser también tratado como prevaricato en algunos casos (López, 2015: 23-24). 
la jurisprudencia. La observación es importante en tanto nos advierte de una transformación fundamental en la comprensión del papel de la jurisprudencia mexicana en el marco del tránsito (y probablemente impulsado por éste) a un Estado constitucional de derecho.

Así pues, a pesar de las resistencias a admitir el papel dinámico de la jurisprudencia, estamos experimentando - en el plano práctico y discursivo, antes que en el legislativo - un cambio sustantivo respecto de la forma en que la concebimos, y su papel en el sistema jurídico, que se ha vuelto más palpable, en mi opinión, por la centralidad de los derechos humanos y la reforma de junio de 2011 en materia de derechos humanos en México.

La incorporación de los derechos humanos en las Constituciones son fuente de legitimidad y justificación de la acción política y jurídica de una comunidad, su reconocimiento a nivel constitucional funge como garantía de la importancia de tales derechos (opuesta al carácter legal ordinario) (Aguiló, 2003: 290). Dicho reconocimiento constitucional como límite condicionante a la interpretación y aplicación del derecho, sumado a la distribución formal de poder de los órganos estatales y los mecanismos de control de la constitucionalidad de leyes, ha dado paso al Estado constitucional de derecho (Atienza, 2004: 75).

Podemos incluso coincidir acerca de la gran importancia del "bloque de constitucionalidad" en México, que en sede judicial ha tenido un desarrollo formidable, dando cuenta así de la incorporación de los derechos humanos, de origen internacional, al catálogo de derechos fundamentales de la Constitución mexicana, y participando incluso de la ampliación del bloque para recibir la jurisprudencia de la Corte Interamericana de Derechos Humanos (Ferrer, 2018: 671).

Sin embargo, el aparente tránsito que en la forma hemos llevado a cabo de un Estado de derecho a un Estado constitucional de derecho no se ha concretado en lo sustantivo, pues la suscripción de dicha configuración no ha logrado que los órganos del Estado mexicano protejan y promuevan efectivamente los derechos humanos. ${ }^{12}$ ¿Qué es entonces lo que hace falta para que esto ocurra si, en teoría, tenemos todos los elementos formales para consumar el tránsito a un Estado constitucional de derecho?

12 Ya advertía Ferrer Mac-Gregor (2018: 664) que el advenimiento del derecho internacional de los derechos humanos y la posterior aparición del control de convencionalidad en el ámbito interamericano estaba generando repercusiones trascendentales para los Estados nación. 
Si bien es cierto que la Constitución mexicana ha experimentado una transformación para recoger los elementos formales necesarios para dicho tránsito, también lo es que, en el sistema jurídico mexicano no ha ocurrido una revisión de otros elementos estructurales del sistema que deberían transitar y acompañar la implementación de estos rasgos del Estado constitucional de derecho.

Tengo en mente a la jurisprudencia de la $\mathrm{SCJN}^{13}$ como uno de esos elementos estructurales sin el cual se advierte difícil el tránsito exitoso a un estado de cosas distinto. En el marco de esta constatación, cobra relevancia la relación de la jurisprudencia con el principio de legalidad, ya que formalmente y de facto, los órganos de la administración pública del Estado mexicano han mantenido y mantienen una adhesión absoluta (al menos en el discurso) a la más estricta legalidad de sus actos.

Esto por supuesto no es algo negativo en sí mismo, habría incluso quizá que celebrarlo; no obstante, dos circunstancias se derivan de la concepción liberal de legalidad que mantenemos:

1) Los órganos judiciales tienen una obligación directa y real de aplicar y actuar conforme al contenido de la jurisprudencia.

2) Los demás órganos del Estado deben actuar con estricto apego a la ley, por tanto, no están obligados a conocer o a aplicar jurisprudencia en el desempeño de sus funciones cotidianas. ${ }^{14}$

Las dos circunstancias previas nos conducen a preguntarnos acerca de quiénes son los destinatarios de la jurisprudencia. Idealmente, los destinatarios de la regla autoritativa serían todos aquellos cuya esfera se pudiera ver alterada con su aplicación o deban intervenir en la misma: tribunales, funcionarios y particulares, en virtud de que, presumiblemente, uno de los propósitos de la emisión de reglas es regular la conducta en algún aspecto necesario (es decir, no se emiten reglas sobre un tema ya regulado).

13 Concretamente, la derivada de los juicios de amparo, dado que las sentencias dictadas en los juicios de acción de constitucionalidad y controversia constitucional pueden tener efectos generales, según los requisitos establecidos por la Constitución y la ley reglamentaria cuando cuenten con mayoría calificada de ocho votos (Ferrer, 2018: 569).

14 Aunque, sin lugar a duda, sería deseable que todos y cada uno de los órganos del Estado conocieran y aplicaran la jurisprudencia como la forma más acabada del derecho vigente.

Esta obra está bajo una Licencia Creative Commons

Atribución-NoComercial-SinDerivar 4.0 Internacional, IIJ-UNAM.

Boletín Mexicano de Derecho Comparado, núm. 155, mayo-agosto de 2019, pp. 799-839. 
En el caso de la jurisprudencia mexicana, sin embargo, la preminencia del principio de legalidad limita el alcance de la regla jurisprudencial únicamente a las partes involucradas y a los tribunales, ya que no obliga a los particulares a invocarla en el futuro ni a las demás autoridades a conocerla o aplicarla directamente. Así, en un sentido, el principio de legalidad afecta el alcance de la jurisprudencia, ya que no sólo impide a las autoridades distintas a la judicial seguirlo y aplicarlo de manera directa, sino que incluso desincentiva entre los particulares el uso y recurso a las reglas de precedente fuera de los espacios jurisdiccionales (Gómora, 2018: 221).

Realmente, los destinatarios de la regla contenida en la jurisprudencia desde la Ley de Amparo, de 1882, son únicamente los tribunales, pues la obligación de aplicarla solamente recae en ellos, aunque no dejamos de observar que, desde hace tiempo, voces al interior de la SCJN han manifestado la pertinencia y necesidad de que las autoridades administrativas funden y motiven sus decisiones también en la jurisprudencia. ${ }^{15}$

En México, su alcance y la obligatoriedad están limitados a tribunales federales y órganos de impartición de justicia locales. Sin embargo, los criterios interpretativos del Poder Judicial contienen la concreción última del derecho vigente, de modo que es deseable que sus efectos y soluciones tuvieran un mayor alcance en consonancia con el tránsito efectivo a un Estado constitucional de derecho.

En la jurisprudencia mexicana es particular, pues su alcance está limitado únicamente a las partes involucradas y a los tribunales, ya que no obliga a los particulares a invocarla en el futuro, ni a las demás autoridades a estar al tanto de ella o aplicarla de primera mano, y la razón de ello es que las actividades de las autoridades de la rama administrativa se rigen por el principio de legalidad. ${ }^{16}$

15 Esta preocupación explícita se manifestó en un artículo académico en 2013, aunque seguramente es una preocupación de tiempo atrás que varios compartimos: "Por lo que se refiere a la obligatoriedad de la jurisprudencia, debe destacarse que todavía las autoridades administrativas no están obligadas a aplicarla al fundar y motivar sus resoluciones (cuestión que debería cambiar en el futuro)" (Ferrer, 2018: 343).

16 En este sentido, la interpretación tradicional, establecida incluso a través de jurisprudencia respecto del contenido de la garantía de legalidad contenida en el artículo 16 constitucional, refiere que la obligación de la autoridad administrativa de fundar sus actos, no incluye hacerlo según la interpretación que de ella se ha establecido en jurisprudencia, lo cual es muy desafortunado (SGJN, 2002, Tesis 2a./J.38/2002). 
Así, aunque la jurisprudencia pretende tener fuerza autoritativa en México y desarrolla la concreción última y más acabada de los derechos, ocurre que el principio de legalidad como lo hemos entendido tiene un efecto limitante en su alcance, pues no sólo limita a las autoridades distintas a la judicial a seguirla de primera intención - debido al estricto apego a la ley-, sino que también evita que los particulares atiendan (fuera del ámbito judicial) las reglas de precedente que proceden de un origen distinto al legislativo.

Es claro que dicha limitante sobre la jurisprudencia afecta de manera general toda función y tarea encomendada a los órganos de la administración pública que presuntamente haya sido objeto de interpretación judicial autoritativa en el pasado. Al ser así, los alcances y consecuencias de esta limitante van más allá de la deficiente protección de los derechos humanos y alcanzan las diversas áreas del derecho que aplican los órganos administrativos. De modo que la eventual remoción de dicha limitante aportaría beneficios a todas esas esferas de acción de la administración, no solamente en materia de derechos humanos.

No obstante, aquí me refiero, de manera particular, a la jurisprudencia en materia de derechos humanos por tratarse de una materia transversal que permea prácticamente todas las esferas del derecho que aplica la administración pública. Dado el carácter transversal y la naturaleza de la jurisprudencia en materia de derechos humanos, es factible reconocer su aptitud como vehículo de transformación, capaz de impulsar un cambio sustantivo de percepción en torno al papel que tiene en nuestro ordenamiento jurídico, de ahí la centralidad que le atribuyo a la institución jurídica.

Si bien es cierto que un cambio de percepción con relación a la jurisprudencia tendría como efecto su aplicación cuando versara sobre derechos humanos, dicho cambio no ha ocurrido, y se antoja complejo. En mi opinión, la transformación que se requiere para la jurisprudencia ha de venir, en general, de comprender su importancia para el cumplimiento de las obligaciones del Estado de promover, respetar, proteger y garantizar los derechos humanos; ha de iniciarse con el impulso que el cambio de paradigma constitucional en derechos humanos ha impreso en diversas dinámicas al interior del sistema jurídico, y de ahí proceder a ampliarse a toda la jurisprudencia. 
Un claro ejemplo del efecto limitante de la concepción que mantenemos del principio de legalidad sobre la jurisprudencia mexicana al que nos referimos, se encuentra en las labores de las juntas distritales como órganos ejecutivos del entonces Instituto Federal Electoral (IFE), ahora INE. Dichas juntas tienen entre sus atribuciones, las vinculadas al Registro Federal de Electores, por ejemplo, la expedición y reposición de la credencial para votar con fotografía de los ciudadanos mexicanos.

Es así que dichos órganos se encargan de la expedición y reposición de tales instrumentos; sin embargo, en año electoral hay un término legal para que los ciudadanos la soliciten, a fin de tener actualizado y completamente integrado el padrón electoral en el momento de la elección.

Durante 2012 (año que fue electoral), aconteció que en la quinta circunscripción plurinominal del Tribunal Electoral del Poder Judicial de la Federación, integrada por los estados de Colima, Hidalgo, Estado de México y Michoacán, las juntas distritales comenzaron a negar la reposición de la credencial de elector a los ciudadanos, sustentando su resolución en el entonces Código Federal de Instituciones y Procedimientos Electorales (COFIPE), hoy LEGIPE (principio de legalidad).

No obstante lo anterior, en ese momento el Tribunal Electoral del Poder Judicial de la Federación ya había expedido la siguiente jurisprudencia:

CRedencial PARA VOTAR. CASOS EN QUE RESUlta PROGEDENTE SU REPOSICIÓN FUERA DEL PLAZO LEGAL. De una interpretación de los artículos 146, 154, 159 y 164 del Código Federal de Instituciones y Procedimientos Electorales, relativos al plazo en que puede solicitarse la reposición de la credencial para votar, se advierte que comprende situaciones ordinarias y no aquellas que pudieran resultar extraordinarias, ya que en el caso de éstas debe regir el principio pro ciudadano conforme al cual ha de prevalecer la aplicación de la disposición legal más favorable. De ahí que si el ciudadano no tuvo la oportunidad de solicitar la reposición de la credencial para votar dentro del término legal, derivado de situaciones extraordinarias como el robo, extravío o deterioro de la referida credencial, acaecidos con posterioridad a dicha temporalidad, debe reponerse para permitir al ciudadano ejercer su derecho a votar en los comicios respectivos (Jurisprudencia 8/2008).

Tal criterio vinculante fue emitido pensando precisamente en los casos extraordinarios, no atribuibles a los ciudadanos, en los cuales las autoridades administrativas electorales debían reponer la credencial de elector 
fuera de los plazos legales. Se trataba pues de una respuesta adelantada a la cuestión que se suscitó en las juntas distritales y protectora de derechos político-electorales.

Fundamentando su actuar en el principio de legalidad, las autoridades administrativas negaron a los ciudadanos la credencial para votar, obligando a cientos de ellos a interponer juicios para la protección de los derechos político-electorales del ciudadano a fin de obtener su credencial, mismos que fueron resueltos por la Sala Regional Toluca del Tribunal Electoral del Poder Judicial de la Federación. Las sentencias, como era previsible, aplicaron la ya conocida jurisprudencia estable y ordenaron a las autoridades responsables a emitir la credencial respectiva.

Este ejemplo es una muestra del efecto limitante que padece la jurisprudencia que, de otro modo, podría haberse aplicado desde un primer momento por las juntas distritales, dada su existencia previa y el conocimiento de la misma por las propias autoridades administrativas. No obstante, esta posición transfiere la carga de proteger derechos (que corresponde principalmente a la autoridad) al ciudadano, forzándole a judicializarlos a fin de estar en posibilidad de ejercerlos. Esto tratándose de quienes tienen la posibilidad de ir a juicio, por lo que cabe esperar que un buen número de ciudadanos no puedan siquiera ejercer este derecho.

En tal sentido, creo necesario revaluar los alcances de nuestra jurisprudencia, ya que al hablar de derechos, cuya configuración final se lleva a cabo en los tribunales, su reconocimiento y ejercicio efectivo se supedita a un largo proceso judicial que terminará ordenando a la autoridad administrativa respectiva el respeto y aseguramiento del derecho examinando, sólo después de obligar al ciudadano a gastar recursos económicos, tiempo y esfuerzo, así como procesos judiciales ${ }^{17}$ (a mi juicio innecesarios) para que

$17 \mathrm{Al}$ respecto, es relevante considerar el estudio cuantitativo efectuado por Héctor FixFierro (2011) respecto del amparo administrativo y la mejora regulatoria, ya que muestra un panorama general de la operación del amparo administrativo promovido contra actos de autoridades administrativas del ámbito federal, local o estatal, mismo que le lleva a confirmar la hipótesis de que una proporción considerable de amparos son innecesarios. El texto expone los altísimos costos públicos y privados, no sólo económicos sino también sociales que se generan por la tramitación de amparos administrativos que podrían haberse evitado con asesoría jurídica preventiva a las autoridades administrativas. Los datos proporcionados son reveladores, pues tan sólo en 2002, los costos públicos y privados que representaron los amparos administrativos resueltos por el Poder Judicial, se estimaron en al menos 3,325 millones de pesos. Y no es menor advertir que los conceptos de violación más frecuentes que llegan al amparo reportados por Fix-Fierro (2011: 1 y 82-83) se refieren a las

Esta obra está bajo una Licencia Creative Commons

Atribución-NoComercial-SinDerivar 4.0 Internacional, IIJ-UNAM.

Boletin Mexicano de Derecho Comparado, núm. 155, mayo-agosto de 2019, pp. 799-839. 
el tribunal vuelva a ordenar lo que ya había establecido en jurisprudencia estable previa.

Como éste, hay muchos ejemplos que revelan la redundancia de los procesos y la ineficiencia estatal en la protección de derechos. ${ }^{18}$ Por lo que cabe preguntarnos, ¿cuál es el sentido de esta práctica? La respuesta no parece ser otra sino desgastar al ciudadano, obstaculizar el ejercicio de derechos, duplicar esfuerzos y gastar recursos públicos y privados para llegar a un resultado conocido de antemano por las autoridades administrativas y establecido en la jurisprudencia estable. Tal práctica es una muestra de los efectos nocivos que conlleva aferrrarse a una noción de legalidad que es insuficiente para el contexto jurídico actual y que no se corresponde con los rasgos de un Estado de derecho constitucional que afirmamos tener.

Es importante observar que, si bien es cierto que el artículo 17 de la Constitución Política de los Estados Unidos Mexicanos prevé la existencia de un servicio de defensoría pública, también lo es que el recurso a esta institución presenta grandes complejidades como lo constantan las investigaciones recientes (Suárez y Fix-Fierro, 2018). Aunado a lo anterior, la materia penal es la materia por excelencia a la que se destina la defensoría pública, y el estado de cosas que guardan las defensorías públicas en las entidades federativas no es alentador según los diferentes indicadores que muestran las disparidades de las legislaciones locales en el diseño de las mismas (Fix-Fierro, 2015).

En este escenario, la propuesta planteada adopta un enfoque previo de mayor alcance que los resultados que la defensoría pública o la suplencia de la queja en el caso del amparo podrían ofrecer a los ciudadanos. Partimos de la premisa de que el ciudadano debe poder ejercer sus derechos y que éstos sean exigibles a las autoridades sin la necesidad de llevarlos a la arena judicial, por lo cual, el remedio idóneo se encuentra en el ámbito competencial y de intervención inicial de cada autoridad estatal.

En dicho sentido, emplear el principio de legalidad para justificar la actuación "limitada" de los órganos de gobierno aplica igualmente para

garantías formales de "fundamentación y motivación", así como a "formalidades esenciales del procedimiento".

18 Véase Palomo Carrasco (2015: 246) para contrastar otros ejemplos en los que ocurre este efecto limitante que pudo haberse evitado con la aplicación oportuna de la jurisprudencia. 
limitar el ejercicio concreto de derechos a los ciudadanos cuando tales derechos han sido ya reconocidos en sede jurisdiccional, como en el caso antes mencionado. Se trata, pues, de una discusión que nos concierne y que debemos sostener en aras de fortalecer nuestras instituciones y el sistema jurídico mexicano.

En México, se ha dicho, prevalece el principio de legalidad previsto constitucionalmente, mismo que - en trazos generales - está instituido como un garante cuya función es establecer límites al ejercicio del poder público (encuentra su fundamento en la Constitución y marco de actuación en la propia ley) que busca proteger la esfera personal de los individuos de intervenciones del Estado no previstas en la ley (Londoño, 2010: 765-766).

Ahora bien, dado que es razonable proteger a los ciudadanos de intervenciones arbitrarias del Estado, el objetor podría replicar cuál es el problema con este estado de cosas. El problema surge cuando se advierte que la obligación constitucional de promover, respetar, proteger y garantizar los derechos humanos de conformidad con los principios de universalidad, interdependencia, indivisibilidad y progresividad de todas las autoridades mexicanas no es realizable o mínimamente alcanzable mientras se mantenga - como hasta ahora - la adhesión a ultranza a una concepción de legalidad anclada en unos presupuestos fundacionales distintos a los que ahora fundamentan nuestra Constitución Política. ${ }^{19}$

Me explico. Al tiempo que la Constitución Política de los Estados Unidos Mexicanos — más decididamente con la reforma constitucional de 2011 - impone una obligación permanente de protección de los derechos humanos a todos los órganos del Estado, ${ }^{20}$ mantiene también una imposición de sujeción al principio de legalidad (según la concepción antes referida), cuya adherencia se ha manifestado históricamente como una adherencia estricta de los órganos administrativos a la letra de la ley. Este rasgo responde a una narrativa específica, como señala Serna (2012: 9-10), acerca del origen, funciones, estructura y justificación del Estado y del derecho presente en el imaginario jurídico-constitucional dominante en México.

19 Gargarella (2017: 211-233) sostiene una tesis que refuerza esta inquietud, la cual estructura teóricamente el problema particular que aquí planteo como traslapes de las etapas del constitucionalismo latinoamericano, como se verá más adelante.

20 Von Bogdandy (2017: 19) alude a esta reforma como un ejemplo vívido del proceso de "internacionalización del derecho constitucional" referida como una de las manifestaciones-aproximaciones del constitucionalismo en la región latinoamericana, junto con el neoconstitucionalismo y el nuevo constitucionalismo latinoamericano. 
Si se mira esta tensión desde la estricta concepción de legalidad de corte liberal ${ }^{21}$ fuertemente arraigada en México, ambos mandatos constitucionales se contraponen y la ejecución de uno de ellos impide el cumplimiento del otro, por lo que alguno de esos mandatos no será ejecutado en la práctica, tal como ha ocurrido. En el dilema de "cumplimiento" ha prevalecido la noción más arraigada en nuestro ámbito jurídico, que se ha afianzado por largo tiempo y que no da muestras de alteración alguna: nuestra concepción del principio liberal de legalidad.

Ahora bien, aunque esta tensión no debería sorprendernos, lo cierto es que en realidad no nos hemos percatado plenamente de su existencia (Gargarella, 2017: 233). Roberto Gargarella (2017) ha explicado este problema a nivel latinoamericano desde las cuatro etapas del constitucionalismo que han tenido lugar en la región: 1) el constitucionalismo experimental (1810-1850); 2) el constitucionalismo fundacional (1850-1917); 3) el constitucionalismo social (1917-1980), y 4) el constitucionalismo de derechos humanos (1980-2000).

De acuerdo con esta explicación, las Constituciones latinoamericanas de cada periodo muestran ciertos rasgos característicos que acompañan las incorporaciones normativas que aportaron. No obstante, a pesar de las diversas transformaciones, los dos rasgos característicos contenidos en las Constituciones latinoamericanas actuales (como en el caso de la Constitución mexicana) que las describen son: una estructura de poder y una estructura de derechos (Gargarella, 2017: 216-217).

En este sentido, podemos afirmar que la Constitución mexicana de 1857 sentó unas bases fundacionales, mientras que la de 1917 incorporó la dimensión social de los derechos, pero la estructura de poder o institucional permaneció inalterada. De entre dichas etapas constitucionales, la de mediados del siglo XIX tuvo gran importancia, al delinear la forma de un gran número de instituciones que prevalecen hoy en día, tal es el caso de la jurisprudencia mexicana, que se incorporó de manera formal en la Ley de Amparo de 1882.

En el trasfondo de esta discusión subyace una tesis crítica que indica que existe un traslape y colisión de instituciones que coexisten, propug-

21 Como ocurre en otras discusiones doctrinales de derecho, se ha olvidado el contexto que dio origen a algunas elaboraciones teóricas y puede ser que sus elementos constitutivos hayan cambiado. A propósito de la relación de derecho internacional con el derecho nacional en el Estado nación (Von Bogdandy, 2012: 25).

Esta obra está bajo una Licencia Creative Commons Atribución-NoComercial-SinDerivar 4.0 Internacional, IIJ-UNAM. Boletín Mexicano de Derecho Comparado, núm. 155, mayo-agosto de 2019, pp. 799-839. 
nando afirmaciones diversas, las cuales pertenecen a diferentes etapas del constitucionalismo latinoamericano. Tal estado de cosas ha generado que las viejas estructuras e instituciones bloqueen las nuevas incorporaciones constitucionales o bien impidan su adecuada implementación (Gargarella, 2017: 228-231).

Obsérvese que la tensión que planteo parece un ejemplo de la tensión que se presenta en términos constitucionales entre instituciones y afirmaciones, que pertenecen a distintas etapas constitucionales, en los términos de Gargarella. Así, tanto la concepción de legalidad a la que me he referido como la jurisprudencia, tuvieron su origen en el constitucionalismo fundacional, en tanto que la ola de transformación comprometida con los derechos humanos es producto del constitucionalismo de derechos humanos; y todos ellos responden, por supuesto, a necesidades e intereses distintos entre sí (Gargarella, 2017: 213 y 223).

La discusión que aquí propongo sugiere modificaciones a esa estructura institucional que impide el pleno desarrollo del llamado constitucionalismo de derechos humanos. En este sentido, sugiero que, con la modificación en la concepción y aplicación en la esfera administrativa del principio de legalidad, así como de la jurisprudencia, se puede lograr una alteración de la estructura institucional que permita acompañar, en lugar de obstaculizar, la implementación efectiva de los derechos humanos. Lo que se pretende es superar el traslape de aspiraciones en conflicto mediante su síntesis y conciliación (Gargarella, 2017: 228).

Debemos reconocer la importancia de esta situación, que sugiere que mientras los aspectos orgánico-institucionales de la Constitución permanezcan inalterados y bloqueen la transformación, no podremos hacer efectiva la Constitución, en tanto no se prevea la reacción y ajuste de las estructuras que las llevan a cabo, por lo que los esfuerzos no fructificarán en tanto no nos ocupemos de la parte orgánica. ${ }^{22}$

Así pues, amparados en nociones del constitucionalismo fundacional mexicano, se ha promovido un falso dilema, en el cual la aceptación y la aplicación en el ámbito de las autoridades administrativas de las interpretaciones del Poder Judicial federal ${ }^{23}$ (lo cual, por cierto, ya ocurre aisladamente) son

22 Claramente, la modificación aquí sugerida es sólo una pequeña parte de los cambios estructurales necesarios para la plena conciliación y síntesis de instituciones, pero una de gran importancia (Gargarella, 2017: 231).

23 En ello coincide Palomo Carrasco (2005: 179), al señalar que “...bajo el pretexto de que las sentencias aisladas de los juicios de que conocen los órganos jurisdiccionales del 
una amenaza al principio de legalidad (administrativa) o incluso una violación al principio de división de poderes.

Ahora bien, cotidianamente se ha pretendido justificar la falta de compromiso de la rama administrativa con la protección efectiva de los derechos humanos, apelando a las limitaciones que el principio de legalidad impone a la autoridad administrativa que, aunado a la imposibilidad de que la jurisprudencia alcance a otras autoridades fuera del ámbito judicial, ${ }^{24}$ dan pie al contexto idóneo para la omisión del cumplimiento de sus propias responsabilidades en materia de derechos humanos. Esta estructura de pensamiento sigue reproduciéndose y afianzándose a sí misma en la rama administrativa del Estado, y es un ejemplo tangible de que "...aunque el derecho es una plataforma para superar la exclusión, también puede ser usada para perpetuarla" (Von Bogdandy, 2017: 6).

En esa concepción y práctica cotidiana de legalidad de la administración pública, por las razones recién expuestas, no tiene cabida (al menos no de manera natural) la maximización de derechos conforme a los principios de universalidad, interdependencia, indivisibilidad y progresividad. Esta constatación está directamente relacionada con las diversas observaciones que desde la Comisión Interamericana de Derechos Humanos se han hecho acerca de la falta de cumplimiento de las autoridades mexicanas de los estándares internacionales en materia de derechos humanos en una larga lista de rubros.

Entre los déficits reportados por la Comisión Interamericana (2018: 11) en el informe de país de 2016, sobre la situación de los derechos humanos en México, se encuentra:

[La] profunda brecha entre el andamiaje legislativo y judicial, y la realidad cotidiana que viven millones de personas en el país, en su acceso a la justicia, prevención del delito, y otras iniciativas gubernamentales. Una y otra vez, en

Poder Judicial de la Federación no obligan a las autoridades administrativas, éstas puedan emitir reiteradamente, sin pena y sin limitación alguna, actos que se encuentran en contra de jurisprudencia firme emanada de la Suprema Corte de Justicia de la Nación o de los tribunales colegiados de circuito...".

24 Esta preocupación es compartida y analizada por Palomo Carrasco (2015: 179), quien, con argumentos afines, aunque diversos a los aquí expuestos, sostiene también la pertinencia de que la jurisprudencia emitida por el Poder Judicial de la Federación vincule a las autoridades administrativas del país. 
todo el país, la CIDH escuchó de las víctimas que la procuración de justicia es una "simulación".

$\mathrm{Al}$ respecto, la Comisión Interamericana (2018: 14) está en lo cierto al afirmar que el reto de México es cerrar la "brecha existente entre su marco normativo y su apoyo irrestricto a los derechos humanos con la realidad que experimentan un gran número de habitantes cuando buscan una justicia pronta y efectiva".

En este contexto, no es sorprendente que la rama administrativa sea la más atrasada en esta implementación de derechos humanos, habida cuenta de que el impulso de su incorporación normativa vino del Legislativo y su aplicación ha sido asumida por el Judicial, sin que haya esfuerzos encaminados a asumir dicha tarea en las esferas de la rama administrativa del Estado, ${ }^{25}$ aun cuando dicha responsabilidad les incumbe como órganos del Estado.

\section{HACIA UNA LEGALIDAD ROBUSTA}

Como he dicho, la particular concepción liberal del principio de legalidad se ha usado en nuestro contexto como "justificación" para el incumplimiento de las obligaciones de las autoridades administrativas (en general todas las autoridades que pertenecen en el ámbito local o federal a la rama ejecutiva) en materia de derechos humanos. Aún más, pues en el pasado se ha advertido que es, incluso, "«legal» que una autoridad administrativa cometa una violación constitucional al aplicar una ley que haya sido declarada inconstitucional por la jurisprudencia de la Corte o por los tribunales colegiados de circuito..." (Palomo, 2015: 186), lo cual resulta absurdo.

En tal sentido, por insuficientes que puedan ser las lecturas al respecto, lo cierto es que el Poder Judicial se ha consolidado y es actualmente la rama del Estado mexicano que más y mejores resultados ha mostrado en lo que a protección de derechos humanos se refiere. No obstante, la otra dimensión de su función, la de establecer criterios estables para la aplicación

25 Es un tema central que no ha pasado desapercibido en la agenda de la Comisión Interamericana de Derechos Humanos y los bajos niveles de cumplimiento de ramas de gobierno diversas a la judicial representan una preocupación vigente, como pude constatar en el "V Seminario Internacional de Supervisión, Cumplimiento e Impacto del Sistema Interamericano de Derechos Humanos", celebrado los días 12 y 13 de julio de 2018 en el Instituto Max Planck, en Heidelberg, Alemania. 
futura del derecho, no logra aportar todas sus bondades en la protección de derechos más allá del ámbito judicial.

El estado de cosas descrito nos obliga a preguntarnos qué se puede hacer al respecto, dado que deseamos alcanzar una protección efectiva de los derechos humanos sin perder los avances logrados en lo que al Estado de derecho se refiere. Se trata pues de una preocupación que se deriva y se vincula con los procesos de internacionalización del derecho constitucional y constitucionalización del derecho internacional reflejada en la incorporación, en las Constituciones domésticas de normas de derechos humanos, como es el caso mexicano. ${ }^{26}$

Pues bien, cabe pensar en la posibilidad de examinar los límites teóricos de nuestra concepción tradicional de legalidad. Recordemos que la delimitación de nuestros conceptos es un proceso artificial que nos permite representar la realidad de cierta manera con el propósito de emplearla para diferentes fines; sin embargo, es posible advertir las limitaciones de tales límites teóricos cuando contrastamos nuestros conceptos con los contextos prácticos (Del Mar, 2008: 128-131).

Nuestros conceptos son centrales para dar forma al derecho, de modo que el análisis de nuestros conceptos es indispensable para alterarlo: la academia se encarga de cuestionar y refinar los conceptos, tales conceptos integran nuestras construcciones teóricas, las cuales, a su vez, informan los sistemas jurídicos modernos (Von Bogdandy, 2017: 5).

Del Mar (2008: 131-132) ha sostenido que el concepto de legalidad ha estado formado (aunque no determinado) por una concreción espaciotemporal, pero también que la concreción teórica de cualquier concepción de legalidad (incluida la nuestra) tiene límites visibles en contextos particulares, lo que lleva a considerar una perspectiva teórica pluralista al respecto, a fin de concebir los posibles y diversos conceptos de legalidad no como rivales, sino como colaboradores potenciales. ${ }^{27}$ Entonces, el objetivo de la pluralidad en este caso, sería emplearla para ofrecer respuestas más robustas a los contextos prácticos. ${ }^{28}$

26 Para una discusión detallada de las tensiones a las que dichos procesos dan lugar en distintos niveles y ámbitos, véase Capaldo, Sieckmann y Clérico (2012).

27 Esta posición es compatible con la explicación de los traslapes constitucionales ofrecida por Gargarella (2017).

28 Afín a esta preocupación, se ha planteado la importancia de cuestionar el papel de los tribunales en el contexto político y social de Latinoamérica en términos de exclusión y debilidad institucional (Von Bogdandy, 2017: 12).

Esta obra está bajo una Licencia Creative Commons Atribución-NoComercial-SinDerivar 4.0 Internacional, IIJ-UNAM. Boletín Mexicano de Derecho Comparado, núm. 155, mayo-agosto de 2019, pp. 799-839. 
$\mathrm{Al}$ respecto, y en el entendido de que la concepción de legalidad que mantenemos en México es una concreción que se dio como resultado del tránsito al Estado liberal de derecho (noción afianzada en el constitucionalismo fundacional), cabe la posibilidad de ampliar nuestro concepto con otras posibles notas que le permitan un desdoblamiento adecuado a la luz de la problemática que se viene analizando.

Se trata, pues, de robustecer el concepto del principio de legalidad de la administración pública ${ }^{29}$ con elementos que nos permitan conceptualizarlo $^{30}$ de manera que se adapte a los requerimientos del Estado constitucional de derecho - que es el momento espacio-temporal en el que nos encontramos-, a fin de que se comprenda la coexistencia de ambos mandatos constitucionales como efectivos y ejecutables.

$\mathrm{Al}$ aceptar esta premisa, la construcción teórica de una noción robusta de legalidad permite considerar a la jurisprudencia estable como fuente central del derecho, ${ }^{31}$ aplicable para todas las autoridades administrativas, y en todos los casos que ésta ofrezca un desarrollo interpretativo protector de derechos humanos que se desprenda de una ley aplicable.

De este modo, una legalidad robusta le concede un papel primario a la jurisprudencia - que desde siempre se le ha negado en detrimento de la protección de derechos en nuestro sistema jurídico - como una extensión de la ley misma, ya que se trata de su propia interpretación, es decir, la versión más acabada de la ley que las autoridades tienen obligación de aplicar de primera mano (Gudiño, 2001: 148).

En definitiva, robustecer el concepto de legalidad permite ampliar el alcance de la jurisprudencia a todos sus destinatarios naturales, más allá de limitarlos a los órganos judiciales, con lo cual se permite que las virtudes de la doctrina judicial estable beneficien a los ciudadanos y que en ese concepto robusto de "legalidad", los órganos administrativos encuentren

29 Colombia ha logrado esto, aunque motivado por razones distintas relacionadas con la congestión judicial (López, 2015: 14).

$30 \mathrm{Al}$ respecto, el Primer Tribunal Colegiado del Decimocuarto Circuito sostuvo en una tesis aislada (Tesis XIV.1o.8 K) que la obligación constitucional de fundar y motivar los actos de las autoridades administrativas debe tomar en consideración la jurisprudencia, que es la interpretación reiterada y obligatoria de la ley.

31 En consonancia con esta idea, Gargarella (2017) ha señalado que las estructuras de poder establecidas a mediados del siglo XIX son un legado muy pesado y negativo para el constitucionalismo actual. 
la vía de cumplimiento de sus obligaciones en materia de derechos humanos, que es un mandato constitucional.

La vía para materializar esta propuesta apunta a dos momentos: el primero en el ámbito doctrinal, dedicado a robustecer el principio de legalidad administrativa para entenderlo en términos más completos; y el segundo, dedicado a impulsar reformas legislativas para modificar el alcance de la jurisprudencia en la Constitución Política de los Estados Unidos Mexicanos y la Ley de Amparo, de modo que las autoridades administrativas adquieran la obligación de aplicar la jurisprudencia estable de primera mano ${ }^{32}$ con el carácter de fuente plena del derecho que le corresponde.

Dicha propuesta es perfectamente compatible con la forma constitucional que suscribimos, pues implica robustecer nuestro concepto de "legalidad" para admitir que las reglas jurisprudenciales ${ }^{33}$ son interpretaciones de la ley, que forman parte de esa misma legalidad. Tal conceptualización más robusta, me parece, va de la mano con la aspiración de materializar un auténtico Estado constitucional de derecho.

Ahora bien, para muchos autores parecería algo "natural" aceptar que el principio de legalidad se ha transformado profundamente en el Estado constitucional de derecho y que, dado que las leyes también están sometidas a la Constitución, cabría esperar que la supremacía constitucional y su control, así como el producto de ese control, fuese visto como aquello que compone el imperio de la ley. Desafortunadamente, esa aceptación no es asumida así fuera del ámbito judicial mexicano, o incluso dentro de él (Ferrer, 2018: 679).

En tal sentido, esta propuesta de robustecer la concepción del principio de legalidad sumado a la ampliación del alcance de la jurisprudencia mexicana, bien puede ser entendida en la lógica transformativa del enfoque del Ius Constitutionale Commune en América Latina (ICGAL), partícipe de la orientación metodológica que mantiene en su núcleo la triada de derechos humanos, democracia y Estado de derecho (Von Bogdandy, 2017: 4-8).

El objetivo transformador del ICGAL pasa por eliminar la brecha en el cumplimiento de protección a los derechos humanos y el fortalecimiento

32 Esto es ya una realidad desde hace varios años con resultados exitosos (López, 2015).

33 Estoy pensando sólo en la jurisprudencia federal, que es obligatoria en todo el país, ya que para imaginar un escenario óptimo en las entidades federativas sería necesario primero resolver la disparidad e ineficiencias de los sistemas de creación jurisprudencial local, ahí donde los hay. 
de las instituciones jurídicas internas, pues como se ha visto, la aceptación estatal de las normas internacionales de derechos humanos, su incorporación en el derecho doméstico y la creación de mecanismos de protección para las personas, no son suficientes para el cumplimiento pleno de dicha obligación (Von Bogdandy, 2017: 10).

Es indispensable tener en cuenta que tanto el constitucionalismo transformador impulsado por el ICCAL como el desempeño del constitucionalismo de derechos humanos, depositan en la judicatura un papel activo y central para la materialización e implementación efectiva. La judicatura está llamada pues, a desempeñar un rol central en esa transformación (Von Bogdandy, 2017: 10) al estar en sus manos la interpretación del derecho de acuerdo con los principios contenidos en la Constitución, e informar con dichas lecturas el sistema jurídico en su totalidad.

Por ejemplo, la igualdad es uno de esos principios que la judicatura ha ido transformando para hacerlo más completo y funcional, de modo que resuelva en la práctica problemas concretos de exclusión que puedan alcanzar a más personas de manera cotidiana. La rama administrativa puede beneficiarse activamente de los procesos argumentativos de la rama judicial, asumiendo y aplicando la jurisprudencia como parte de la legalidad, permitiendo así que más personas reciban de primera mano sus beneficios como la forma más acabada de los derechos (Aldao, 2017: 95).

Ahora bien, este proceso de robustecer el principio de legalidad es perfectamente compatible con el principio de la división de poderes y la democracia representativa. La propuesta sugerida parte del respeto a la división de poderes, ya que, gracias a ella, el Legislativo emite las leyes que el Judicial aplica y en ocasiones interpreta. Esta descripción es una imagen cotidiana de la interacción entre ambos poderes.

Si bien es innegable que el Estado moderno está anclado en el principio de la separación de poderes, cuya función ha sido siempre limitar al poder para evitar su ejercicio abusivo (García Roca, 2000: 44), en este sentido, la asignación de tareas específicas al Ejecutivo, Legislativo y Judicial explica la manera en que cada uno opera como contrapeso del resto. No obstante, es prudente matizar la lectura del sentido original de este principio, pues ni en la concepción clásica se hablaba de una tajante división del poder, lo cual habría sido inviable (García Roca, 2000: 47).

Algunos constitucionalistas refieren que las estructuras y configuraciones constitucionales actuales han superado la noción clásica del principio 
(Fix-Zamudio, 1967: 30 y 64; García Roca, 2000: 56). Dicha superación hace referencia a que nos encontramos en un entorno constitucional mucho más rico y complejo, en el que el principio de división de poderes se ha de entender mejor en clave de cooperación e interdependencia de los diversos órganos del Estado, toda vez que la protección de la libertad hoy en día no depende de manera exclusiva de la división de poderes (García Roca, 2000: 48; Cossío, 2008: 103).

Esta lógica hace eco del marco constitucional de la división de poderes en México, que ilustra los equilibrios que como nación hemos buscado. Así, un dato a tomar en consideración es que, históricamente, la preocupación por controlar los excesos de los poderes ha estado centrada en el Ejecutivo y el Legislativo - como advierte Héctor Fix-Zamudio- ya que, si en la Constitución de 1824 el énfasis y la concentración de poder se inclinaba hacia el Legislativo, la redacción de la Constitución de 1857 como la de 1917 claramente reforzaban de varias formas la posición del Ejecutivo federal (Fix-Zamudio, 1967). ${ }^{34}$

Lo relevante de esta observación es advertir que nuestra historia constitucional no ha registrado al Poder Judicial como un órgano proclive a la acumulación de poder, sino más bien tendiente a conservar (si bien con sus altibajos) cierto grado de autonomía e independencia respecto de los otros poderes; por ejemplo, al fungir como institución protectora de los derechos fundamentales de los particulares durante el porfiriato (Fix-Zamudio, 1967: 44). Dicha observación pone en perspectiva la preocupación de invasión de competencias o violación a la división de poderes local.

Así pues, los elementos de cooperación, interdependencia y protección de derechos como los ejes rectores del principio de división de poderes no se contraponen a una legalidad robusta, sino que refuerzan la idea de que la aplicación de jurisprudencia por los órganos de la administración pública es parte de la legalidad robusta deficitaria del sistema de valores constitucional.

$34 \mathrm{Al}$ respecto, es ilustrativa la observación del maestro Fix-Zamudio (1967: 45 y 102103) acerca de la influencia que tuvieron las ideas de Emilio Rabasa en el Constituyente de 1917, en cuanto a que los tribunales federales no eran un verdadero poder al carecer de iniciativa, unidad y autoridad general. La historia constitucional y esta percepción absorbida por el Constituyente permiten comprender que, en el frágil mantenimiento nacional de la divisón de poderes, la fórmula más segura haya sido acotar las actividades del Judicial a administrar justicia bajo la "fórmula Otero" para excluir con ello cualquier sospecha de funciones legislativas por parte del Poder Judicial. 
El funcionamiento y la actividad de cada rama del poder público continúa dirigida a sus respectivas funciones, con la adición de que en el constitucionalismo de derechos humanos es una necesidad y una realidad verificada, el papel interpretativo y aplicativo de los jueces en el contexto local. Podría decirse que son el vehículo para trasladar los avances internacionales en derechos humanos a los ciudadanos de a pie, pero esta noción no adquiere pleno sentido hasta que imaginemos que cada ciudadano puede acceder al ejercicio más pleno de sus derechos, a través de cualquier autoridad y respecto de cualquier petición.

Esta noción equivale a estructurar nuestra institucionalidad en torno a la protección de derechos humanos, no solamente en el ámbito judicial, sino incluso dando pleno cumplimiento al compromiso estatal y constitucional asumido de respetar, proteger, promover y garantizar los derechos humanos. Así, la propuesta permite una colaboración más cercana de los poderes para acercar a las personas la versión más acabada a la que pueden acceder de sus derechos, unidos en una misma finalidad, que es la protección más efectiva.

En mi opinión, la propia objeción adquiere matices distintos cuando se la mira a la luz del constitucionalismo que México ha abrazado e incorporado. Esto es así porque la idea de invasión de competencias del Poder Judicial con la interpretación del derecho fue una noción igualmente que perteneció a otro constitucionalismo, ajena al tipo de necesidades que el constitucionalismo actual presenta, de modo que invocarla implica negar uno de los rasgos característicos de nuestro propio constitucionalismo.

$\mathrm{El}$ constitucionalismo de los derechos requiere una nueva institucionalidad, un trabajo colaborativo de los esfuerzos de cada rama del gobierno en ese objetivo común. Se trata pues de una adopción consciente y seria de acciones colaborativas para potenciar y afianzar el ejercicio de los derechos humanos, acciones que se pretende vengan desde la administración pública en ejercicio de la legalidad robusta que les corresponde ejercer en el marco del constitucionalismo señalado.

Las obligaciones en materia de derechos humanos, que ha de asumir la administración pública, son compatibles y realizables desde la concepción de la legalidad robusta de la que hablamos. Si esto es así, al aplicar la jurisprudencia - desde una legalidad robusta - la administración pública daría cumplimiento a su obligación de respetar, proteger, promover y garantizar los derechos humanos, alineando su actuación al sentido material 
de la Constitución, al tiempo que preservaría la justificación originaria del principio de legalidad, a saber, proteger a los particulares de los abusos de la autoridad.

Si el objetivo de un Estado constitucional de derecho es precisamente garantizar y promover los derechos humanos; si el Poder Judicial de la Federación cotidianamente garantiza y promueve los derechos humanos de los justiciables con sus resoluciones, como la Constitución lo mandata, incluso de manera progresiva. Si cada rama del poder público tiene una obligación de protección y promoción de derechos humanos en el desempeño de sus funciones, entonces, al aplicar la concreción más acabada de la ley - que es la jurisprudencia - como parte del mandato constitucional de aplicar el derecho, se está dando un paso adelante en el afianzamiento real del Estado constitucional con lo que éste conlleva.

De modo que, al examinar la viabilidad de la propuesta, vale la pena recordar que, desde 2009, Pedro Salazar hablaba de nuestra etiqueta como un auténtico Estado de derecho en sentido formal pero no en lo que hace a la parte material de aplicación real del derecho (Salazar, 1998: 204). Con esta idea en mente, tantos años después cabe preguntarse si acaso las acciones tomadas hasta ahora nos han conducido efectivamente a un auténtico Estado de derecho constitucional, si queremos serlo y si estamos dispuestos a emprender las acciones que se requieren para serlo. Ésta es una de ellas.

\section{CONCLUSIONES}

El trabajo aquí expuesto ha mostrado el proceso transitado por la jurisprudencia y el principio de legalidad en el contexto mexicano, intentando revelar las tensiones en su interacción y los obstáculos que la actual configuración de estas nociones presenta para el efectivo cumplimiento de la obligación de protección y garantía de los derechos humanos que tiene el Estado mexicano.

Mostré que la concepción de legalidad que mantenemos y que aplican las autoridades administrativas mexicanas, corresponde a una concreción espacio-temporal anterior que no responde a las necesidades de nuestra actual forma constitucional de ser. Por esta razón, conviene discutir y transitar a una forma robusta de legalidad adecuada para un Estado de derecho constitucional. 
En tal sentido, sostuve que requerimos implementar acciones concretas en el tránsito hacia un efectivo Estado de derecho constitucional. Sugerí que una de esas acciones concretas es robustecer nuestra concepción del principio de legalidad y ampliar el alcance de la jurisprudencia estable del Poder Judicial de la Federación, a fin de que las autoridades administrativas puedan aplicarla.

Ambas acciones son necesarias para lograr una efectiva protección de derechos humanos también desde el ámbito de la autoridad administrativa, y constituyen un paso contundente en la reingeniería institucional que, sin lugar a dudas, requerimos para lograr que el Estado de derecho constitucional se exprese adecuadamente en México.

Así pues, la idea es que de primera mano todas las autoridades - en el ámbito de sus competencias y materias - apliquen jurisprudencia que proteja, delinee, desarrolle y amplíe el ejercicio de los derechos humanos parece coexistir con un Estado constitucional de derecho. Por lo cual, debe ser una responsabilidad primaria de las autoridades del Estado mexicano el conocer y aplicar la jurisprudencia en su ámbito de competencia como parte de las normas jurídicas que la legalidad demanda.

Esta implementación traería consigo enormes avances, pues permitiría, entre otras cosas:

- Beneficiar a los ciudadanos con la aplicación directa de la jurisprudencia en sus interacciones con los entes de la administración pública.

- Potenciar el ejercicio de derechos, al tiempo que la autoridad administrativa recibe los beneficios de la experiencia judicial mediante el diálogo entre órganos de gobierno.

- Fortalecer la jurisprudencia derivado de potenciar su uso.

- Retirar la gravosa carga impuesta a los ciudadanos de llevar al ámbito judicial asuntos que pueden ser resueltos con ayuda de jurisprudencia estable directamente con la autoridad administrativa.

- Evitar la judicialización innecesaria para garantizar a las personas el ejercicio de los derechos humanos.

- Evitar imponer una carga adicional en los ciudadanos que se ven obligados a gastar recursos para estar en posibilidad de ejercitar un derecho cuando se trata de derechos que ya son plenamente reconocidos por la jurisprudencia. 
- Optimizar esfuerzos y recursos del Estado, y así evitar reenvíos innecesarios al prevenir potenciales violaciones a derechos al tiempo que se da coherencia y unidad a la actuación del propio Estado.

- Aprovechar mejor las capacidades del Estado al trabajar conjuntamente y aplicar la jurisprudencia del Poder Judicial de la Federación en los asuntos de la competencia de los órganos del Estado que se trate, que ya han sido ampliamente discutidos, resueltos y reiterados por el Poder Judicial.

- Cumplir adecuadamente con el mandato constitucional de garantizar la protección más amplia a los derechos humanos, partiendo de la presunción de que - de acuerdo con el mandato del artículo 1o. constitucional - el Poder Judicial interpreta las normas relativas a derechos humanos de acuerdo con la propia Constitución y los tratados internacionales. Por lo cual, no hay razón para negar el carácter supremo que la interpretación tiene contenido en la jurisprudencia del Poder Judicial de la Federación.

- Internalizar y socializar adecuadamente entre los órganos del Estado las implicaciones que conlleva su obligación constitucional y convencional de promover, respetar, proteger y garantizar los derechos humanos.

- Avanzar como Estado en el cumplimiento de las obligaciones internacionales adquiridas en materia de protección de los derechos humanos.

Es cierto que robustecer el principio de legalidad puede encontrar resistencias; sin embargo, se debe considerar que esta propuesta no requiere una actuación indebida de la autoridad administrativa, sino sólo aquello que exige la actual configuración constitucional, la cual demanda una actuación administrativa acorde con las responsabilidades estatales en materia de derechos humanos. La buena noticia es que México ya cuenta con una institución de suficiente solidez que puede servir como una herramienta para tales efectos, que es la jurisprudencia, misma que hasta ahora ha sido subutilizada.

En suma, se promueve que todos los niveles de gobierno, y los ciudadanos, se beneficien del alcance protector de la jurisprudencia, permitiendo que ésta despliegue su pleno potencial como una herramienta que, de manera natural, impulsa la protección de derechos al configurar y delinear 
su concreción. En mi opinión, éstas son suficientes razones para buscar un cambio de concepción y ampliar el alcance de la jurisprudencia.

Con todo, el Estado mexicano no estaría más que tomando medidas para el efectivo cumplimiento del compromiso internacional contraído con la firma de la Convención Americana sobre Derechos Humanos, al adoptar las medidas legislativas y de otro carácter que son necesarias para hacer efectivos los derechos y libertades contenidos en la Constitución Política de los Estados Unidos Mexicanos y en la propia Convención.

\section{BIBLIOGRAFÍA}

Acosta Romero, Miguel y Pérez Fonseca, Alfonso, 1998, Derecho jurisprudencial mexicano, México, Porrúa.

AGuiló Regla, Josep, 2003, "Sobre el constitucionalismo y la resistencia constitucional”, Doxa, núm. 26.

ALDAO, Martín et al., 2017, "A Multidimensional Approach to Equity in the Inter-American Context: Redistribution, Recognition and Participatory Parity", en Von BOGDANDY, Armin et al. (eds.), Transformative Constitutionalism in Latin America, Nueva York, Oxford University Press.

Atienza, Manuel, 2004, El derecho como argumentación, México, Fontamara.

Bergalli, Roberto, 1998, "Principio de legalidad: fundamento de la modernidad", Jueces para la Democracia, núm. 32.

Burgoa Orihuela, Ignacio, 2004, El juicio de amparo, 40a. ed., México, Porrúa.

Cabrera Acevedo, Lucio, 2002, El Constituyente de 1917 y el Poder Fudicial de la Federación. Una visión del siglo XX, México, SCJN.

Castro Zavaleta, Salvador, 197 1, Práctica del juicio de amparo: doctrina, formularios y jurisprudencia, México, Cárdenas.

CLÉRICO, Laura, 2015, "Examen de proporcionalidad y objeción de indeterminación", Anuario de Filosofía del Derecho, núm. 31.

Comisión Interamericana De Derechos Humanos, 2015, "Situación de Derechos Humanos en México", Informe de país, OEA/Ser.L/ V/II.Doc.44/15.

Cossío DíAz, José Ramón, 2008, "La función constitutiva de los tribunales constitucionales y la división de poderes", Anuario de Derecho Constitucional Latinoamericano, núm. 14. 
Del Mar, Maksymilian, 2008, "The Spatio-Temporality of Objectification in Legal Theory: Concepts of Legality between Theory and Practice", Problema. Anuario de Filosofia y Teoría del Derecho, núm. 2.

Ferrer MaG-Gregor, Eduardo, 2018, Panorámica del derecho procesal constitucional y convencional, Madrid, Marcial Pons-UNAM.

FIX-FIERRO, Héctor, 201 1, El amparo administrativo y la mejora regulatoria, México, UNAM, Instituto de Investigaciones Jurídicas.

FIX-FiERro, Héctor, 2015, "Hacia una defensa pública de calidad. El nuevo diseño institucional de las defensorías públicas en las entidades federativas de la República mexicana", Cuestiones Constitucionales, núm. 32.

FiX-Zamudio, Héctor y Cossío DíAZ, José Ramón, 2003, El Poder Fudicial en el ordenamiento mexicano, México, Fondo de Cultura Económica.

FiX-ZAMUDiO, Héctor, 1967, "Valor actual del principio de la división de poderes y su consagración en las constituciones de 1857 y 1917 ”, Boletín del Instituto de Derecho Comparado de México, núm. 58-59.

García DE ENTERRÍA, Eduardo y FernánDEZ, Tomás-Ramón, 1974, Curso de derecho administrativo I, 12a. ed., Madrid, Thomson-Civitas.

GARCÍA DE ENTERRÍA, Eduardo, 1984, "Principio de legalidad, estado material de derecho y facultades interpretativas y constructivas de la jurisprudencia en la Constitución", Revista Española de Derecho Constitucional, vol. 4, núm. 10.

García Ricai, Diego, 2011, Estado de derecho y principio de legalidad, México, GNDH.

GARCÍA RoCA, Javier, 2000, "Del principio de la división de poderes", $R e$ vista de Estudios Políticos, 108.

GARGARELLA, Roberto, 2017, "The «New» Latin American Constitutionalism. Old Wine in New Skins”, en Von BOGDANDY, Armin et al. (eds.), Transformative Constitutionalism in Latin America, Nueva York, Oxford University Press.

GÓMORA JuÁrez, Sandra, 2018, "La ejemplaridad y proyección del precedente", Problema. Anuario de Filosofia y Teoría del Derecho, vol. 1, núm. 12.

GÓMORA JuÁrez, Sandra, 2018, Un análisis conceptual del precedente judicial, México, UNAM, Instituto de Investigaciones Jurídicas.

GudiÑo Pelayo, José de Jesús, 2001, Ingeniería judicial y reforma del Estado, México, Laguna.

Guerrero Lara, Ezequiel y GuAdarrama López, Enrique (comps.), 1984, La interpretación constitucional de la Suprema Corte de Fusticia (19171982), México, UNAM, Instituto de Investigaciones Jurídicas.

Esta obra está bajo una Licencia Creative Commons Atribución-NoComercial-SinDerivar 4.0 Internacional, IIJ-UNAM. Boletín Mexicano de Derecho Comparado, núm. 155, mayo-agosto de 2019, pp. 799-839. 
Hernández, María del Pilar, 2008, "La jurisdicción constitucional. Estudio de macrocomparación", en FERRER MAG-GregOR, Eduardo y ZALDÍvar LelO DE LARREA, Arturo (coords.), La ciencia del derecho procesal constitucional. Estudios en homenaje a Héctor Fix-Zamudio en sus cincuenta años como investigador del derecho, t. III, México, UNAM, Instituto de Investigaciones Jurídicas.

Herrera García, Alfonso, 2015, La intepretación de los derechos humanos y sus garantías por la Suprema Corte de Justicia. Una aproximación jurisprudencial, México, CNDH.

Kelsen, Hans, 1979, Teoría general del derecho y del Estado, trad. de Eduardo García Máynez, México, UNAM.

LONDOÑo LÁZARO, María Carmelina, 2010, "El principio de legalidad y el control de convencionalidad de las leyes: confluencias y perspectivas en el pensamiento de la Corte Interamericana de Derechos Humanos", Boletín Mexicano de Derecho Comparado, nueva serie, año XLIII, núm. 128.

LóPEz MEDINA, Diego, 2015, "Obediencia judicial y administrativa de los precedentes de las Altas Cortes en Colombia: dos concepciones del fin y uso de la jurisprudencia como fuente del derecho", Precedente, núm. 7.

MÁRQUEz GÓMEZ, Daniel, 2005, Función jurídica de control de la administración pública, México, UNAM, Instituto de Investigaciones Jurídicas.

PAlOMO GARRASco, Óscar, 2015, La observancia obligatoria de la jurisprudencia emanada de la Suprema Corte de Justicia de la Nación y de los tribunales colegiados de circuito en los actos administrativos, México, UNAM, Instituto de Investigaciones Jurídicas.

Rubio Llorente, Francisco, 1993, "El principio de legalidad", Revista Española de Derecho Constitucional, núm. 39.

SALAZAR, Pedro, 1998, "Una aproximación al principio de legalidad y su vigencia en México”, Isonomía, núm. 9.

SERNA, José María, 2012, Impacto e implicaciones constitucionales de la globalización en el sistema jurídico mexicano, México, UNAM, Instituto de Investigaciones Jurídicas.

Serra Rojas, Andrés, 1998, Derecho administrativo, 19a. ed., México, Porrúa.

SuÁrez Ávila, Alberto Abad y FiX-Fierro, Héctor, 2018, "El servicio profesional de carrera en la defensoría pública en México", Política y Gobierno, vol. 25, núm. 2. 
Suprema CORTE de Justiaia de LA NAGión, 2005, La jurisprudencia en méxico, 2a. ed., México, SCJN.

Valencia Carmona, Salvador, 1995, Derecho constitucional mexicano a fin de siglo, México, Porrúa-UNAM.

VignOlo Cueva, Orlando, 2011, "La cláusula del Estado de derecho, el principio de legalidad y la administración pública. Postulados básicos y transformaciones", Boletín Mexicano de Derecho Comparado, nueva serie, año XLIV, núm. 131.

Von Bogdandy, Armin et al. (eds.), Transformative Constitutionalism in Latin America, Nueva York, Oxford University Press.

VON BOGDANDY, Armin, 2012, "Del paradigma de la soberanía al paradigma del pluralismo normativo. Una nueva perspectiva (mirada) de la relación entre el derecho internacional y los ordenamientos jurídicos nacionales", en CAPALDO, Griselda et al. (coords.), Internacionalización del derecho constitucional, constitucionalización del derecho internacional, Buenos Aires, Eudeba. 